\title{
The Criticality Of Cultural Awareness In Global Marketing: Some Case Examples
}

Kenneth A. Hunt, Fort Lewis College, USA

William Hodkin, Fort Lewis College, USA

\begin{abstract}
International trade has taken place for thousands of years. One might assume that with such a long history, those involved with international business would have learned how it is done. For the most part, the major players are sensitive to cultural differences and how important it is to conduct business within the boundaries of the prevailing culture. However, there are hundreds of examples of cultural faux pas. This paper focuses on some of the top trading partners with the United States and the business opportunities that they represent. It also addresses general business etiquette guidelines that should be understood and applied when working with the key trading partners. Several cultural business missteps are presented to illustrate that the simplest decision can lead to embarrassment or worse, major economic loss. The need to research foreign cultural and language differences is just as important as researching the market for sales opportunities. In the global marketplace, the players who are aware and sensitive to the culture of their trading partners have a greater probability of success, than those who do not.
\end{abstract}

Keywords: Global Marketing; Cultural Influence; International Marketing; Global Case Examples; Culture as a Business Variable

\section{INTRODUCTION}

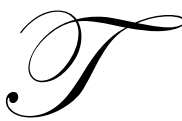

he old adage that it is a small world has never been truer than it has been in the last twenty years. High-speed jumbo jets, the Internet, cell phones, and satellite television have brought the whole world to our fingertips. We now can order products directly from a manufacturer on the other side of the world with the push of a few keys and have the product on our doorstep overnight. All this new technology and the related global business is a boon to advanced world economies as well as to developing nations who are technologically adept.

The shrinking world and rapidly expanding global business environment on the other hand can be a figurative minefield of business mistakes and cultural blunders which can cost businesses millions of dollars. Even the largest and most well funded global enterprises can fall victim to the lack of understanding of the new and ever expanding global markets as shown by the following recent and true business example.

Consider the case of a large German automobile company previewing a newly completed and very expensive Super Bowl television commercial. The company has invested millions of dollars designing and building a new line of environmentally friendly "green" cars, and the company is sing the biggest media event, the Super Bowl, to get the word out to the general public. Half way through the one minute, million-dollar commercial the company realizes that what is supposed to be a satirical parody of a mythical eco-police squad, (the Green Police), arresting people for driving an environmentally unfriendly automobile, actually conjures up memories of the Nazi police units, also called "The Green Police", that rounded up Jews and sent them off to the death camps. Should the ad run as planned? Should the company scrap the promotion with only three weeks to go and start over? The choice could result in great cost to the company. Rather than basking in the glory of a very well developed advertising promotion for selling a state of the art automobile, the company's cultural insensitivity may create overwhelming negative publicity. Cultural awareness could have prevented the situation. 


\section{THE GLOBAL ECONOMY}

In order to understand how likely it would be that a business falls victim to this type of cultural slip-up, it is important to first look at the size of the global markets. According to the US Department of Commerce Bureau of Economic Analysis (International Economic Accounts, 2010) the United State's balance of trade in 1992 was represented by a deficit of $\$ 39.2$ billion and by December 2009 the total trade deficit in goods and services had climbed to $\$ 380.66$ billion. A closer look at the underlying figures reveals that the United States exported $\$ 1.55$ trillion to foreign countries and businesses. At the same time The US imported approximately $\$ 1.93$ trillion. The figures from 1992 to 2009 indicate however, that during the 17-year period US exports and imports increased from $250 \%$ and $294.7 \%$, respectively. In spite of the net deficit to the GDP of the United States that these figures represent, the figures indicate there is a global economy which is increasing in size each year. The businesses that are best positioned to operate internationally will be able to capitalize on the increasing global opportunities. Businesses positioned to operate internationally not only have the infrastructure in place to support global business operations, but they are also aware of the cultural differences between trading partners. As shown by the German automaker example above, misunderstanding the culture of the target market can have disastrous effects when it comes to successful product marketing.

\section{KEY US TRADING PARTNERS BY IMPORTS/EXPORTS}

To learn how US companies can minimize the possibility of making cultural missteps or miscalculations in the global business environment, it is important to look at the key trading partners of the United States. The list of the key partners also includes the total dollar volume of US imports/exports, the types of goods and services each one buys/sells to the US, and some examples of ill-conceived business proposals, marketing plans, or just outright bad planning. The list is not complete in terms of cultural etiquette but is intended to provide a general sense of how each respective country views visiting businessmen and businesswomen. The list is generally organized by ranking based on import volume in U.S dollars.

Canada - Imports from US \$224.51 billion - Exports to US \$171.7 billion (US Trade Balance, by Partner Country 2009; Imports, exports and trade balance of goods on a balance-of-payments basis, by country or country grouping, 2010)

Canada is the largest importer of American goods. Primary opportunities for American businesses include sales of passenger cars and automotive accessories, special purpose vehicles, industrial machinery, civilian aircraft, engines and engine parts. Canadian companies are diverse and have great loyalty to the region in which they are based. Canadian businessmen are reserved and polite. Canadians generally like to follow protocol during meetings and negotiations. Visiting business people should shake hands upon arrival and departure at all meetings. Men should also shake the hand of women attending meetings.

- $\quad$ Titles are normally not used in the majority of Canada, but they are important in Quebec which is more formal. Business cards are exchanged at the beginning of meetings. When transacting business in Quebec, one side of the business card should be in French.

- $\quad$ Canadians are usually not driven by emotion in business therefore it is important to come to all meetings very prepared, armed with the facts, figures and supporting data to help make the point of the meeting. Relying solely on promises will not win contracts in Canada.

Notable business issues: (Ricks, D. A., 2000)

During the opening ceremonies of a Toronto Blue Jays baseball game, the US Marine Color Guard made the mistake of displaying the Canadian Flag upside-down. This did not result in the loss of a business contract, but it did point out how ignorant Americans can be concerning our neighbors to the north.

The Hunt-Wesson food company introduced the Big John brand in Canada without thinking that something as simple as a product name may cause problems. Big John in French translates as "Gros Jos." "Gros Jos" is a 
French expression that signifies a woman with large breasts. It is reported that sales did not suffer badly because of the increased number of men purchasing "Gros Jos."

A manufacturer of canned fish ran an advertisement in Quebec showing a woman in shorts playing golf with a man. The ad stated that the woman could play golf and still get home in time to prepare a dinner of canned fish that evening. The campaign failed because women did not wear shorts on the golf course, nor did they play with golf men at the time. Additionally, canned fish was almost never served as the main course for dinner.

China - Imports from US \$295.54 billion - Exports to US \$65.1 billion (US-China Trade Statistics and China's World Trade Statistics, 1996-2010)

It is clear from reading newspapers and listening to the nightly news that China is one of the biggest purchasers of US debt. China also has, over the last 30 years become one of the strongest economies in the world. The changing demographics in China and the increasing individual wealth are opening up tremendous opportunities for global business to attempt to break into the Chinese markets. Opportunities for American business in China include potential sales of electrical machinery and equipment, power generation equipment, oil seeds and oleaginous fruits, aircraft, plastics, optics and medical equipment, iron and steel and paper goods. These items represent the majority of the \$295.54 billion in imports to China in 2009 .

- Chinese business culture operates on a concept of "face" which loosely translates to dignity, prestige, honor, etc. It is very important for one doing business in China to avoid losing face or causing the loss of face. There are four types of "face" in China.

1) Gei-mian-zi: this is when one shows face to others by showing respect.

2) Jiang-mian-zi: this is when one's face is increased to others, possibly by complimenting someone to an associate.

3) Diu-mian-zi: this is when your way of doing business has been shown to people.

4) Liu-mian-zi: this face is made by avoiding mistakes and making wise decisions.

- $\quad$ Business meetings and the necessary greetings are very formal. Honorific titles and surnames are always used and the senior person in the room is always acknowledged first. Shaking hands is the most common form of greeting but the Chinese will usually look toward the ground and not make eye contact.

- Given the formal nature of business it is a general practice to schedule meetings in writing one or more months in advance. The Chinese always use agendas for business meetings. Do not expect to make quick progress with a Chinese businessman. Relationships are solidified once the person gets to know you. Communication during meetings is always official. Arrive at all meetings early as arriving late is considered an insult. The use of colors during presentations is discouraged. Presentations should always be in black and white as colors have meaning to the Chinese.

- $\quad$ During business negotiations only the senior member of the party should speak. Any written material should be in both Chinese and English and should have been reviewed by a translator prior to any meeting. Written translations must be accurate and cannot be misinterpreted.

Notable business issues: (Ricks, D. A., 2000) include:

Understanding translation from your native language is a major source of business mistakes. Examples

i) A Chinese shoe manufacturer was trying to make its shoes more attractive to Egyptian purchasers by including Arabic characters on the soles (bottom) of the shoes. The Chinese designers just copied random characters without understanding the true meaning of the words. The words they used translated as "God" which resulted in a major problem for the company.

ii) Kentucky Fried Chicken (KFC) discovered a major translation problem when they introduced the slogan "finger lickin' good" in China. It seems their slogan, when translated, means "eat your fingers off." Needless to say, the slogan was scrapped in China. 
iii) The Chinese do not tolerate advertising that is not truthful. Toyota ran ads based on an old Chinese proverb that states "when you get to the foot of a mountain a road will appear." Something was lost in the translation and the ad said, "Wherever there is a road, there is a Toyota." Chinese authorities informed Toyota that they were guilty of false and misleading advertising because "China has roads but there are not necessarily Toyotas on them." At great expense, Toyota learned the lesson.

Mexico - Imports from US $\$ 176.3$ billion - Exports to US \$105.7 billion (Workman, Mexican Furniture Gives Mexico Half-Billion Trade Advantage, 2010)

The North American Free Trade Agreement (NAFTA) was implemented in January, 1994 with the goal of eliminating barriers to investment and trade between the USA, Canada and Mexico. Upon implementation, tariffs were eliminated or reduced on more than half of US imports from Mexico and more than one third of US exports to Mexico. The passage of NAFTA instantly opened up many new opportunities in Mexico for US business people. The primary exports from the US to Mexico include: electrical machines and parts, automobile parts and accessories, plastic, computer accessories, semi-conductors and industrial supplies and machinery. American tobacco is the fastest growing export to Mexico. There are many other items exported to Mexico from the US but these listed above make up the majority of the $\$ 105$ billion currently reported in trade.

- Doing business in Mexico requires the right business contacts for success. After the initial introduction, senior business leaders usually are not involved with business meetings. If the senior business leaders are no longer involved in the negotiations, one will know that they are finally getting somewhere with the process. The senior people will however make the final decision.

- Business dress in Mexico is similar to that in Europe. Men typically wear conservative dark shaded suits while women typically wear business suits or conservative dresses.

- $\quad$ Business cards are printed in Spanish on one side and English on the other side. Cards are presented to everyone during the initial meeting. Interestingly, business cards should contain your professional and educational accomplishments.

Notable business issues: (Ricks, D. A., 2000)

When Parker Pen marketed a ballpoint pen in Mexico, its ads were supposed to have read, "It won't leak in your pocket and embarrass you." Instead, the company thought that the word "embarazar" (to impregnate) meant to embarrass, so the ad read: "It won't leak in your pocket and make you pregnant."

Chicken magnate, Frank Perdue's line, "It takes a tough man to make a tender chicken," ended up being very embarrassing to the company when translated into Spanish. The translated saying means, "It takes a sexually stimulated man to make a chicken affectionate."

The Coca-Cola Company had a popular advertising campaign with the slogan, "Catch the wave." This was translated into Spanish and put on billboards throughout Mexico. Unfortunately, Coca-Cola quickly discovered Mexicans also understood the translation to mean "have diarrhea." The campaign was pulled at a cost of several millions of dollars.

The Dairy Associations' "Got Milk" ads can be funny, especially when they are used without being reviewed by a local language expert in Mexico and other Spanish speaking countries. In Spanish "Got Milk" translates as "Are You Lactating?" (Are You Lactating?, 2009).

Japan - Imports from US $\$ 96.0$ billion - Exports to US \$47.07 billion (Workman, Japan's Trade Buddies, 2007)

For years, the Japanese have been a significant trading partner with the United States. In the fifties it seemed that just about everything imported into the US that was reasonably priced, came from Japan. Today, China has taken over as the leader in providing low cost items to the US. Japan is still a source of tremendous import/export business for US companies. Japan's main imports include machinery and equipment, fossil fuels, chemicals, textiles and beef. Japan now exports mainly to other Asian countries. 
The Japanese culture is similar in many respects to that of China. It is a reserved and relationship driven business culture. Doing business in Japan is very difficult for foreigners unless you have a good correspondent who can guide you through the culture. Foreign business representatives are not really expected to speak Japanese or completely understand cultural protocol. Mistakes are tolerated as long as genuine respect is shown at all times.

- $\quad$ Saving face is very important in Japanese society. The Japanese will never do or say anything that may cause loss of face; consequently they will not criticize, insult, or put anyone in an uncomfortable position during business negotiations. Face can be both lost and earned. It can be earned by speaking praise and appreciation.

- $\quad$ Non-verbal communication is also very important in Japan. The Japanese have published a book for foreigners which describe how to interpret business "signs." It is usually considered disrespectful to stare into someone's eyes; to stare at someone who is senior.

- The Japanese will speak while maintaining an impassive expression. They will listen almost expressionless. A frown while listening can be interpreted as disagreement. Other expressions to note as a negative reaction include: inhaling though clenched teeth, scratching the back of the head or eyebrows and tilting the head back.

- Japanese are very conscious of status and age. There is a very distinct hierarchy in the family and the extended family as well as a social or business group. The elder of the group is always revered and honored. They will always be specially treated in social situations.

Notable business issues: (Ricks, D. A., 2000)

The American slogan for Salem cigarettes, "Salem-Feeling Free," was translated into the Japanese market as "When smoking Salem, you will feel so refreshed that your mind seems to be free and empty."

Japanese auto executives at the opening of a new factory in Kentucky were presented with the Kentucky Flag. After opening the flag and showing it to all involved with the ceremony, the Japanese executive carelessly dragged it along the ground. In Japan, flags are not treated with the same respect as they are in America. A better understanding of American culture would have prevented this embarrassment.

The Kinki Nippon Tourist Company, Japan's second-largest tourist agency was mystified when it entered English-speaking markets and began receiving requests for unusual sex tours.

An automobile rental company in Tokyo decided to prepare a brochure in English to help drivers with the proper rules of the road. Something was apparently lost when the instructions were translated to English reading, "When passengers of foot heave in sight, tootle the horn. Trumpet him melodiously at first, but if he still obstacles your passage, then tootle him with vigor."

Germany - Imports from US $\$ 69.8$ billion - Exports to US $\$ 40.2$ billion (Workman, Engineering Excellence Drives Germany's International Trade Success, 2008)

The German economy is one of the most successful in the world. Germany has many trading partners worldwide in addition to the US Opportunities for US businesses in Germany include imports of fuel oil, nonmilitary aircraft, liquid natural gas, coal and non- metallic minerals. Exports to the US include cars, medical, dental and pharmaceutical supplies, security equipment, and testing and control devices.

German business is very formal. Appointments are always required and should be established at least one to two weeks in advance. The first meetings are usually for the purpose of getting to know the players to determine trustworthiness. Direct eye contact is appreciated and English is an accepted language. It would be a good idea to have a translator with the negotiating team at all meetings. The senior member of the business team always enters the room first and men will enter before women if they are about the same age. Other notable business advice includes: 
- A weak handshake gives others the impression that you are insecure and not convinced of your abilities. A firm handshake sends a message of trust, frankness, sincerity, consideration and honesty.

- Everyone has a personal distance zone that surrounds them, and unexpected intrusions into this zone are unwelcome.

- $\quad$ Do not sit at a meeting until being invited to sit and being told where your place at the table is located.

- $\quad$ Most business meetings will have very strict agendas which will be followed.

- $\quad$ Germany is very heavily regulated and bureaucratic. Be patient with the process.

- Germans are detail oriented and will try to learn every minute detail of a proposal or plan.

Notable business issues: (Ricks, D. A., 2000)

Studebaker introduced a new car to Germany in 1927 called the "dictator." It was successful until 1936 when the German politics of the time required that they discontinue the product line. After Hitler it is very unlikely that anything called the Dictator will be introduced in Germany.

The Rolls Royce Company built a luxury car called the Silver Mist. The name and product were successful in England but were experiencing problems in Germany. After studying the acceptance problem, the company determined that the translated term "mist" means "excrement" in German. Obviously the Germans did not find this a good thing to drive regardless of the luxury.

A trade magazine that promoted giftware was launching circulation in Germany. The word gift was in the title as part of the magazine's name. Gift in German means poison, which prompted a rather myopic company executive to comment, "The Germans should find a new word for poison." One wonders how long he was employed.

Goodyear prepared an ad for German consumption showing that the Goodyear tires are so strong that they can break steel chains. In Germany it is illegal to imply that someone else's product is inferior. Because it was decided the ad was knocking German chain manufacturers, the government required Goodyear to stop the campaign.

The following example is not an example of a cultural blunder but one caused by poor research. (Ricks, D. A., 2000). A large fast food company was looking for a location with a "high traffic count" to open a new fast food outlet. After looking at the three final choices, the company purchased the location with the most drive-by traffic and built the facility. After opening, management was surprised by the extremely slow pace of sales given the traffic in the area. It was later determined that the traffic counts were accurate; however, the traffic was going to the Bordello which was located nearby. The drivers did not have fast food on their mind.

France - Imports from US $\$ 33.9$ billion - Exports to US $\$ 24.4$ billion (Workman, Most Popular products traded between France and America, 2007)

French imports from the United States have increased more than 27\% since 2002. There are currently over 61 million people in France which is one of the top markets for goods and services produced in the United States. Some of the notable goods produced in the US and sent to France include, aircraft engines, pharmaceutical preparations, aircraft parts, medicinal equipment, industrial machines, computer accessories and measuring and testing equipment.

The French culture is lower keyed than many of its European neighbors. They do expect a high degree of courtesy and some formality but it is not as intense as Germany and others. It is unwise to be over friendly when doing business in France. The French usually separate their personal and business lives. Meetings in July and August should be avoided as these are the typical months when French businessmen take vacation. Men should dress understated and stylish in dark colored business suits. Women should wear either business suits or dresses in soft colors.

Other business advice includes: (France - French Culture, Customs and Etiquette) 
- $\quad$ Appointments should be scheduled in advance and the resulting meetings are to discuss issues and not to make decisions.

- $\quad$ Most important business decisions are made at the top levels of the company.

- $\quad$ Formal business agreements will be very comprehensive and precisely worded.

- $\quad$ Wait to be told where to sit.

- $\quad$ Be patient and do not become frustrated by strict adherence to protocol.

- $\quad$ Understand that discussions may become heated and intense.

- $\quad$ Avoid high-pressure sales efforts. Present a low key, detailed proposal that will explain all the advantages of what is being sold.

- $\quad$ French business cards are larger than ones from other countries and should include advanced academic degrees.

Notable business issues: (Ricks, D. A., 2000) not in France.

Gerber, the name of the famous baby food maker, is also the French word for vomiting. Gerber is therefore

Colgate-Palmolive was trying to introduce its Cue toothpaste in France. After checking with its French speaking advisors the plans were shelved until something could be worked out with the name. Cue is a pornographic word in French.

The makers of Pet milk had problems when marking its product in French speaking countries. The word "pet" in French means "to break wind."

The McDonalds Corporation holds its restaurant owners in the United States to very high standards of cleanliness. In France less emphasis is placed on cleanliness which became the subject of litigation as the French business grew. McDonalds felt its French partner was impacting its world image due to the high number of complaints it was receiving from its US customers traveling to France. An acceptable resolution was reached after lengthy litigation.

A large US coffee company was trying to introduce instant coffee in France. After researching the market in great detail the company learned that coffee plays a major role in the French home. The company also learned that the preparation of "real" coffee is the job of the French housewife so instant coffee would not be a consideration in the morning routine.

Saudi Arabia ${ }^{1}$ - Imports from US \$21.4 billion - Exports to US \$10.2 billion (Workman, Saudi Arabian Exports \& Imports, 2008)

It is no secret that Saudi Arabia is the leading exporter of petroleum products worldwide. They own approximately $20 \%$ of the world's proven oil reserves and account for $90 \%$ of the Middle Eastern exports. US business enjoys the lead in the goods and services that Saudi Arabia imports each year. Goods and services sent to the country include: passenger cars, industrial engines, drilling and oil field equipment, industrial machinery, chemicals, heavy earth moving equipment, civilian aircraft, and measuring, testing and control equipment.

Saudi Arabia is where Islam was born and is visited by millions of Muslims each year. Because of the influence of Islam in both the business and personal lives of Saudi citizens, doing business with the Saudis can be very difficult. Many social, cultural, and business decisions are driven by adherence to Islamic laws which can be very rigid and restrictive when compared to the west.

\footnotetext{
1 Saudi Arabia is \#19 on the list of trading partners by imports but has a unique culture with many potential cultural pitfalls for US businesses, and therefore has been included.
} 
In order to enter the country you must be sponsored. Your sponsor will act as an intermediary and will arrange appointments with the people that you need to meet for your business purposes. Saudis will stand close to you while conversing and you may feel as if your personal space has been violated. This is normal in the Middle Eastern nations. Saudis will spend a great deal of time getting to know you. You must be patient as they prefer to work with people they know and trust. Should you be invited to a Saudi home, arrive on time, dress conservatively, remove your shoes when entering and greet the elders first. Most meals will be taken on the floor. Sit crossed legged or kneel on one knee and eat only with the right hand. Try everything served and do not be surprised if there is no dinner conversation. Other business considerations include: (Saudi Arabia - Language, Culture, Customs and Etiquette, 2010)

- $\quad$ Saudis will most likely judge you on appearances so you should dress and present yourself well.

- $\quad$ Continually repeating your main points will be interpreted that you are telling the truth.

- $\quad$ Do not use high pressure and understand that decisions are easily overturned.

- $\quad$ Expect to be "low-balled" by the Saudi buyer initially and "high balled" by the Saudi seller.

- $\quad$ Disputes are best avoided - although Saudi law recognizes contracts, the problem is you may be faced with a five-year wait before it gets to court.

- $\quad$ Use business cards translated into Arabic and give one to everyone you meet.

- $\quad$ Make sure you check all translations very carefully.

- $\quad$ Businessmen will be expected to wear a suit and should dress well to make a good impression.

- Women wear loose fitting clothes to cover their collarbones and to ensure that their knees are covered.

- Never show an Arab the bottom of your shoe. It is the lowest part of our body and by intentionally showing it to another person it indicates that you feel that person is beneath you. Remember the President Bush shoe-throwing incident? It was a statement by the thrower that President Bush was worthless. It was a big deal in the Arab world but was only considered an assault in the western world.

Notable business issues: (Ricks, D. A., 2000)

In Saudi Arabia, the law prohibits the wearing of neck jewelry by men, and westerners have been arrested for neglecting to observe this rule.

If a visitor brings a gift of food or drink to an Arab household, the hosts may be offended because such gifts imply that they cannot afford such items or are not trusted.

It would be a mistake to refuse a cup of coffee in Saudi Arabia. The Saudi's may consider that a rejection of such a friendly offer would be an affront to them personally. The perception of the person that he was slighted by the refusal for coffee may make any pending business negotiations more difficult.

\section{CONCLUSION}

The fact that a global economy exists is undeniable. Many businesses, large and small are thriving by selling and buying on a global scale. Those businesses that truly understand the opportunities and the potential pitfalls associated with global business will receive the greatest benefit.

The examples provided above are sometimes silly and sometimes very significant. They are real missteps made by real businesses. Each example points out the need to prepare, plan, and understand what your business is trying to accomplish when dealing with other cultures. Hiring the right people to advise you about cultural differences and business practice is a must. In the global marketplace, the best prepared will win.

\section{TEACHING NOTES}

The importance of understanding cultural differences in global marketing is undeniable. This manuscript with case examples could be a valuable tool in a number of different classes. For instance, a consumer behavior class could benefit from the examples of how culture influences behavior and the perceptions of right and wrong. A 
marketing strategy class could benefit from recognizing that strategy is cultural dependent. That is, the marketer must be culturally aware before attempting to devise a strategy. A business to business class could benefit from the examples of meeting and negotiating norms. Attempting to negotiate outside these norms may have disastrous effects. And finally, a global marketing class could obtain obvious benefits from the examples given in this manuscript.

Regardless of the class chosen as the appropriate outlet for this manuscript and case examples, a caveat must be expressed. Some of the examples given may be considered humorous or even silly. It is incumbent upon the professor to emphasize the examples are real and the mistakes made were made by reasonably intelligent human beings. The final conclusion is that business people should always become culturally aware before attempting to conduct international or intercultural business.

\section{AUTHOR INFORMATION}

Kenneth A. Hunt Ph.D. is a Professor of Marketing at Fort Lewis College, Durango, Colorado. Dr. Hunt received his Ph.D. in Marketing from Virginia Tech. He has published over forty articles in such Journals as: the Journal of Retailing, the Journal of the Academy of Marketing Science, and the Journal of Business Research. Email: hunt_k@fortlewis.edu. Corresponding author.

William Hodkin is a successful businessman who has over 30 years' experience in the banking and real estate industry. His management positions included Executive vice president for GE Capital Asset Management Company and American Savings in California. In 2007 he enrolled at Fort Lewis College as a non-traditional student to complete his undergraduate degree in Management. He graduated at the top of his class, summa cum laude in May of 2010. He is a member of Phi Kappa Phi and Beta Gamma Sigma Honor Societies which acknowledge the top students in schools of business throughout the United States. Mr. Hodkin currently lives in Pagosa Springs, Colorado.

\section{REFERENCES}

1. $\quad$ Are you lactating? (2009, 10 22). Retrieved 3 16, 2010, from IDNBLOG: http://idnblog.com/2009/10/22/lactating-native-idn-translation/

2. $\quad$ France - French Culture, Customs and Etiquette. (n.d.). Retrieved 3 6, 2010, from kwintessential: http://www.kwintessential.co.uk/resources/global-etiquette/france-country-profile.html

3. Imports, exports and trade balance of goods on a balance-of-payments basis, by country or country grouping. (2010, 3 11). Retrieved 3 16, 2010, from Statistics Canada: http://www40.statcan.gc.ca/101/cst01/gblec02a-eng.htm

4. International Economic Accounts. (2010, 2 24). Retrieved 2 27, 2010, from Bureau of Economic Analysis: http://www.bea.gov/international/index.htm\#trade

5. $\quad$ Ricks, D. A. (2000). Blunders in International Business - David Ricks 2000. Blackwell Business.

6. US Trade Balance, by Partner Country 2009. (n.d.). Retrieved 3 6, 2010, from United States International Trade Commission: http://dataweb.USitc.gov/scripts/cy m3 run.asp

7. US-China Trade Statistics and China's World Trade Statistics. (1996-2010). Retrieved 3 6, 2010, from USChina Business Council: http://www.USchina.org/statistics/tradetable.html

8. Workman, D. (2008, 228). Engineering Excellence Drives Germany’s International Trade Success . Retrieved 3 16, 2010, from Top German Exports \& Imports: http://importexport.suite101.com/article.cfm/top german exports imports

9. Workman, D. (2007, 1 5). Japan's Trade Buddies. Retrieved 3 14, 2010, from Top 15 Japanese Export \& Import Partners : http://internationaltrade.suite101.com/article.cfm/japan_s trade buddies

10. Workman, D. (2010, 2 24). Mexican Furniture Gives Mexico Half-Billion Trade Advantage. Retrieved 38 , 2010, from Mexico Imports and Exports 2009: http://import-export.suite101.com/article.cfm/mexicoimports-and-exports-2009

11. Workman, D. (2007, 4 26). Most Popular products traded between France and America. Retrieved 36 , 2010, from Top French Exports \& Imports: http://international-tradeleaders.suite101.com/article.cfm/top_french_exports_imports 


\section{NOTES}

